\title{
Yes-tradition and no-tradition in the reproduction of cultural forms and cultural identity in conditions of globalization
}

\author{
Vladimir Gladyshev ${ }^{1}$, Ekaterina Miliaeva ${ }^{1 *}$, Marina Meniaeva $^{2}$, Vera Neveleva $^{2}$ \\ ${ }^{1}$ South Ural State University, 454080 Chelyabinsk, Russia \\ ${ }^{2}$ Chelyabinsk State Institute of Culture and Arts, 454091 Chelyabinsk, Russia
}

\begin{abstract}
The article is devoted to the problem of preserving cultural forms that ensure the reproduction of cultural identity in the conditions of globalization tendencies towards unification and innovation. The purpose of the article is to substantiate the role of yes-tradition and no-tradition as mechanisms of reproduction, transmission and actualization of socially significant cultural content and cultural identity. It is stated that in the era of globalization, the boundaries of cultures become plastic, intercultural interaction contributes to the emergence of «globalized» cultural forms (for example, the brand is among them) which are characterized by signs of cultural standardization. These forms blur cultural identity, threatening cultural security, and therefore meet resistance as a response, where notradition is manifested. The authors believe that the reproduction of the most significant cultural forms ensures the preservation of cultural identity. Yestradition is directly related to the broadcast of reproduction and preservation experience.
\end{abstract}

\section{Introduction}

Modern culture is developing in conditions of two increasing and opposing trends in the context of globalization process. The first trend is connected with technological novation and innovation - this is a tendency towards unification. The second trend becomes a defensive reaction to it, which is expressed in the desire to preserve cultural identity as a value; its realization involves appealing to traditions.

Traditions are the accumulation and transfer of sustainable forms expressing ideological attitudes, value-semantic orientations and sociocultural experience. Traditions are a source of cultural identity that provides a person with sustainability, gives the necessary support in the world of «fluid modernity», where its very identity can be «fluid».

Identity implies the manifestation of consent, that is, the acceptance and separation of what is valuable in the cultural experience of a people (for example, basic values, ideological attitudes). But in order to preserve the boundaries of identity, a moment of disagreement is needed. That disagreement is rejection of a critical attitude to some part of the content

\footnotetext{
* Corresponding author: miliaevaeg@susu.ru
} 
enshrined in the tradition of socio-cultural experience due to its irrelevance, semantic gap with the new content of life. The presence of the moment of disagreement does not violate the continuity. It does not destroy the cultural identity, but provides the «liveliness» to the tradition and its associated cultural forms and their organic incorporation into the current cultural context.

\section{Yes-tradition and No-tradition in conditions of globalization}

The content of the «tradition» concept consists of the stable forms of fixation and the mechanisms of cultural content transmission. They perform communicative and integrative functions: they broadcast both external (superficial) and internal (semantic, essential). These forms establish the connection of times, both horizontal (in one time period) and vertical (in different time periods). Sustainable forms act as a communicator and are in demand in situations of imbalance, loss of stability, in moments of social tensions, challenges and threats.

The nature of tradition contains an antinomy. On the one hand, the tradition «acts as a necessary condition for the preservation, continuity and sustainability of human existence, a prerequisite and a constitutive principle for the formation of the identity of a person, a group or a whole society» [16]. On the other hand, tradition is perceived as a symbol of immutability, since it «preserves» the past. In this connection, tradition is contrasted with novation and innovation. However, conservatism is not a barrier to innovation, if it defends the transmission of socially significant cultural experience, and ensures the preservation and reproduction of the fundamental elements of culture and its security. In this case, the adherence to tradition as a disagreement with noveltyч means socially responsible behavior, concern for the future, suggesting the need for a humanitarian examination of innovations.

In our opinion, it is possible to argue whether traditions are significant, useful or harmful for life, similarly with what Nietzsche writes in his work «On the Use and Abuse of History for Life». Distinguishing three «sorts» of history (monumental, antiquarian and critical), F. Nietzsche suggests using history for «positive» purposes as «useful» for life [15]. Everything that is connected with history, in his opinion, should not constrain the life forces and energies of people living at the moment. Otherwise, the past takes possession of the present, suppresses it. Primarily, history is important because it can and should serve life. This applies to the tradition, the existence of which is impossible outside of history. Tradition gains even more power when it is transmitted not mechanically, but in the living creative effort of its participants, creating their own unique and unrepeatable culture in all its diversity.

There are different types of traditions (for example, reflective, positive, «author's tradition» etc.). A special kind of tradition is the so-called «negative tradition, i.e. based not on the affirmation of any values, but on the denial of values unacceptable for a given culture or subjects» [7].

Firstly, let us note the importance of the thesis that tradition can be associated not only with acceptance, but also with hostility, rejection of something. Secondly, let us point out two sociocultural policies and a kind of «sociocultural paradigms - agreement and disagreement» [13]. They have value, as they allow people to orient and adapt themselves; therefore they take root in culture. In this case, it is possible to distinguish the yes-tradition and the no-tradition. It seems that both are equally important for the existence of culture and being of the person. Yes-tradition expresses the experience of consent, i.e. accepting something as meaningful, valuable in the cultural experience of the people. No-tradition enshrines the cultural experience of disagreement. «No» is a denial of agreement in a word and deed and is an opposition to it. However, «no» also means refusal as a conscious abstinence, a restriction that allows you to hold on to an extent. It has a positive meaning. In 
other words, in spite of the fact that agreement and disagreement are opposite to each other in sense, both contain a positive meaning.

If the experience of disagreement captures the rejection of what threatens a safe and sustainable existence and creative development, then it must be preserved, so it can become a tradition, take root in the culture as no-tradition.

The experience of disagreement, enshrined in the no-tradition, is in fact the experience of consent. So, people can agree with each other in their general disagreement with what is alien to them, what is perceived as distant and destructive in relation to their «life world» and identity. People agree that they do not accept such ways and forms of existence, communication and activity. To say «no» to something together is to show consent in aversion and act responsibly towards your world, society, and your culture [1,3]. Tradition consolidates this general rejection, it means «no» through what is included in the content of various prohibitions, taboos [18]. In this sense, no-tradition performs culture-protective and security functions in relation to cultural and personal identity.

It can be spoken about yes-tradition and no-tradition at different levels (from individual to global) and in different areas (economic, social, political, cultural, religious, environmental, etc.). In a situation of globalization, there is a «resistance», opposition to unification, disagreement with some of its tendencies. This contributes to the preservation of unique origins in different cultures; its diversity is a resource for human development.

\section{Brand as a cultural form: from innovation to tradition}

Since tradition is considered by us as «fixation and transmission mechanism of cultural content» [7], this content itself is associated with the diversity of cultural forms that are reproduced and broadcasted in culture at the local and global levels. Cultural forms are understood as «individual specific historical phenomena of one or another newborn methods and products of socially significant human activity or interaction» [6]. The cultural form is highly functional, since its appearance is always associated with the request for new cultural patterns, values, norms, means of human activity, that exist in a particular socio-cultural situation. The cultural form is polysemantic, multifunctional and ambivalent. The cultural form is gradually ritualized in socio-cultural practices as it is being embodied in a specific cultural object. The object itself accumulates semantics and becomes a tradition. The cultural form goes from the birth as an innovation idea to its implementation in a particular culture and social practice as it serves as a response to actual social demand[4, 9]. The time of this journey today is rarely stretched for a long time; usually it ranges from several hours to several months.

In modern culture, one of the current and highly functional social and cultural forms is the brand. It is a structural entity; its stable features are reproduced in culture every time. However, they may have different content, depending both on the identity of the creator of the brand, and on the requests of its consumer. Therefore, it is necessary to take into account that a more adequate understanding of the brand as a cultural form can only be implemented in its natural cultural context - a modern society dominated by consumption and mass culture $[12,19]$.

We regard the brand as a peculiar value guide, a regulator in the process of the implementation of human consumption practices, both material and spiritual; as a mental construct containing a whole set of meanings, and also as a symbolic construct, which stands for its creator - the human [5]. The brand is a creative product, since it expresses the ideas of the creator related to the satisfaction of immediate human needs. It acts as a mediator not only between the person and the brand reference point, but, more importantly, between person and person, the creator and the consumer. A person consuming a thing also consumes what stands behind it: the meanings, values, goals, life priorities, attitudes, etc., as well as the 
energy that the brand creator invested in it.

The existence of the human is inextricably linked with the objective forms - things, signs, symbols, and human - is a fundamentally objective creature. The brand as a cultural form was brought to life by the need to create a utilitarian product in the conditions of the market relations spreading, that prioritize the relations of production and consumption of things. But in their development, brands are gradually filled with symbolic meanings, with a special place that belongs to their creators, because even in the market-mediated relationships, a person feels a demand for a genuine human nature. Thus, behind the Apple logo and gadgets, involvement in the world of technical and economic geniuses is understood, and behind the classic «little black dress» there is an image of Coco Chanel, that helped many generations of women, including modern, to find ways to express their uniqueness through everyday things.

The emergence of a brand as a sociocultural phenomenon at the turn of the XX - XXI centuries is associated with a change in consumer practices, their transformation into practices of self-expression. In everyday life modern human uses things that not only symbolize power and social status, but also convey individual tastes, preferences [14], and even some imaginary biography of a person who is not indifferent to the brand. Brands that a person focuses on become factors in his identification, a story about who he is or who he wants and can be. Therefore, today the manufacturer is trying to achieve maximum compliance of the proposed product with the identity of the consumer, in connection with it a gradual «impersonality» overcoming of the product and the manufacturer is happening.

Probably, a brand may cease to be a symbol of the alienated state of a human consumer in relation to the commodity world, and therefore, in part, to his life world in general. On this basis it is possible to establish consensus in communication at the global level $[8,10,17]$.

A brand as a no-tradition is fully capable of unifying and standardizing traditional cultural identity. This can be considered as a challenge and even a threat to the cultural security of countries and nations [11]. But in our opinion, the brand contains a certain humanistic potential, which lies in the fact that the modern person has a desire to consume associated with the desire for the full development of themselves. Focusing on different brands and their symbolic meanings allows a person today to feel «embedded» in the global society and world culture. At the same time, a person retains its individuality, freedom and the full potential of infinitely variable behavior. This is the essence of the yes-tradition.

\section{Conclusion}

The demand for yes-traditions and no-traditions is obvious in the situation of aggravating global contradictions. These contradictions are connected to the tendency to unificate different cultures and the opposing tendency to preserve these differences by spreading innovative cultural forms that the brand belongs to. Both tendencies have a vital and constructive power. These traditions are life-affirming and positive as mechanisms of reproduction, transmission and actualization of socially significant cultural content and cultural identity. Both traditions ensure the safe existence of unique origins in a culture, which is essential to its sustainable development. The relevance of the answer in the form of yes-tradition and no-tradition to the challenge of globalization is beyond doubt, since the rejection of all that is destructive in favor of the constructive, contributes to the preservation of culture and cultural identity. Brand as a cultural form contains a constructive potential. Confronting the erosion of cultural identity through the development of a human principle involves reliance on the yes-tradition and the no-tradition. Therefore, yes-tradition and notradition play a decisive role in culture today. This allows consolidating the brand as a cultural form in a constructive sense and thereby preserving cultural identity in the context of a consumer society and mass culture. 


\section{References}

1. M.R. Abdulla, Culture, Religion, and Freedom of Religion or Belief, Review of Faith and International Affairs, 16 (4), 102-115 (2018).

2. Z. Bauman, Liquid modernit (Piter, Saint-Petersburg, 2008).

3. G. Baumann, The Multicultural Riddle: Rethinking National, Ethnic and Religious Identities (Routledge, London, 1999).

4. I. Bosisio, Religion, culture, nation: Possible articulations from three commemorative days. Horizontes Antropológicos. DOI: 10.1590/S0104-71832018000300008. http://www.scielo.br/scielo.php?script=sci_arttext\&pid=S010471832018000300199\#aff1 (accessed 10 July 2019) (2018)

5. A.Dydrov, et al., Brand in the philosophical sense: From object to person, International Journal of Engineering and Technology, 7, 135-139 (2018). DOI: 10,14419 / ijet.v7i4.38.24339

6. A. Flier, Culturegenesis (Russian Institute of Cultural Studies, Moscow) http://yanko.lib.ru/books/cultur/flier-kulturogenez-81.pdf (accessed 10 July 2019).

7. A. Gricanov, World Encyclopedia: Philosophy (ACT, Moscow, 2001).

8. G. Hill, H. Ibsen, Brand (Penguin, London, 1996).

9. R. Grillo, Cultural essentialism and cultural anxiety. Anthropological Theory, 1 (2), 157-173 (2003) DOI: 10.1177/1463499603003002002

10. S.A. Hurrell, D. Scholarios, The People Make the Brand»: Reducing Social Skills Gaps Through Person-Brand Fit and Human: Resource Management Practices, Journal of Service Research, 17 (1), 54-67 (2014). DOI:10.1177/1094670513484508

11. N. Klein, No logo: Taking Aim at the Brand Bullies. Canada: Vintage. (2000)

12. R. J. Lifton, The Protean Self. Human Resilience in an Age of Fragmentation (Basic Books, N.Y., 1993).

13. M. Meniava, V. Neveleva, The socio-cultural paradigm of consensus as the basis for the future strategy of future, Gorizonty gumanitarnogo znaniya, 3, 55-69 (2017). DOI: 10.17805/ggz.2017.3.6

14. C. Nelson, Beyond prometheus: Creativity, discourse, ideology, and the Anthropocene, Knowledge Cultures, 6 (2), 111-131 (2018). DOI: 10.22381/KC6220188

15. F. Nietzshe, The Use and Abuse of History for Life: http://nietzsche.ru/works/mainworks/history/ (accessed 10 July 2019) (1874)

16. V. Tolstyh, Tradition. New Encyclopedia of Philosophy: http://terme.ru/termin/tradicija.html (accessed 10 July 2019) (2000)

17. S. Petrilli, Identity, freedom, and answerability in the global world: A semiotic approach, Semiotica, 171, 97-114 (2008). DOI: 10.1515/SEMI.2008.069.

18. H. Silverman, Contested Cultural Heritage: Religion, Nationalism, Erasure, and Exclusion in a Global World (Springer International Publishing Basel, 2010).

19. E. Trufanova, Human in the labyrinth of identities, Voprosy filosofii, 2, 13-22 (2010). 